\title{
Dietary Inflammatory Index is Associated with Excessive Body Weight and Dietary Patterns in Subjects with Cardiometabolic Risk
}

\author{
Talitha Silva Meneguelli ${ }^{1}$, Jéssica Viana Hinkelmann ${ }^{1}$, Juliana Farias de Novaes ${ }^{1}$, \\ Carla de Oliveira Barbosa Rosa ${ }^{1}$, Mariana De Santis Filgueiras ${ }^{1}$, Brenda Kelly Souza Silveira ${ }^{1}$, \\ Nitin Shivappa ${ }^{2,3,4}$, James R Hebert ${ }^{2,3,4}$, Helen Hermana Miranda Hermsdorff ${ }^{1, *}$ \\ ${ }^{1}$ Department of Nutrition and Health, Universidade Federal de Viçosa, Minas Gerais, Brazil \\ ${ }^{2}$ Cancer Prevention and Control Program, University of South Carolina, Columbia, SC, USA \\ ${ }^{3}$ Department of Epidemiology and Biostatistics, Arnold School of Public Health, University of South Carolina, Columbia, SC, USA \\ ${ }^{4}$ Connecting Health Innovations LLC, Columbia, SC, 29201, USA \\ *Corresponding author: helenhermana@ufv.br
}

Received April 14, 2019; Revised May 26, 2019; Accepted July 11, 2019

\begin{abstract}
Unhealthy eating habits can trigger chronic inflammation in organs and tissues, and subsequent cardiovascular risk. Thus, this study aimed to evaluate the potential association of Dietary Inflammatory Index (DII ${ }^{\mathrm{TM}}$ ) score with cardiometabolic risk factors and $a$ priori and a posteriori dietary patterns in adults and elderly Brazilians (42 \pm 16 years) from a health care program. This cross-sectional study was carried out with 248 individuals (138 women and 110 men) from a Cardiovascular Health Care Program of the Universidade Federal de Viçosa (PROCARDIO-UFV, ReBEC ID number: RBR-5n4y2g). Sociodemographic and clinical characteristics, lifestyle and anthropometric data were assessed by standardized protocols. DII scores were calculated from a 24 h-recall, and dietary patterns were determined by a posteriori method, as Principal Component Analysis (PAC), and $a$ priori method, as Healthy Eating Index (HEI). The mean DII was $0.15 \pm 0.84$. The subjects included in the most pro-inflammatory category(3rd tertile) were more likely to be individuals with excessive body weight, increased waist-to-hip ratio and lower quality diet assessed by PAC and HEI. The most pro-inflammatory diet was associated with excessive body weight as well as other worse dietary patterns.
\end{abstract}

Keywords: Dietary Inflammatory Index (DII $\left.{ }^{\mathrm{TM}}\right)$, Healthy Eating Index (HEI), Principal Component Analysis (PCA), dietary patterns, cardiometabolic risk, inflammation

Cite This Article: Talitha Silva Meneguelli, Jéssica Viana Hinkelmann, Juliana Farias de Novaes, Carla de Oliveira Barbosa Rosa, Mariana De Santis Filgueiras, Brenda Kelly Souza Silveira, Nitin Shivappa, James R Hebert, and Helen Hermana Miranda Hermsdorff, "Dietary Inflammatory Index is Associated with Excessive Body Weight and Dietary Patterns in Subjects with Cardiometabolic Risk." Journal of Food and Nutrition Research, vol. 7, no. 7 (2019): 491-499. doi: 10.12691/jfnr-7-7-2.

\section{Introduction}

Unhealthy eating habits and deleterious lifestyles, such as smoking and sedentariness, may trigger chronic inflammation thereby contributing to increased cardiometabolic risk and development of chronic noncommunicable diseases (CNCD), such as cardiovascular diseases (CVD), diabetes mellitus (DM) and cancer [1-5]. According to World Health Organization (WHO) in 2016, CNCD accounted for 41 million deaths, among these 17.9 million (44\%) were by CVD, 9 million (22\%) by cancer and 1.6 million (4\%) by diabetes [6].

In turn, dietary pattern analysis allow the combination of foods consumed by a population and the identification of both protective and harmful dietary factors for the development of CNCD $[3,7,8]$. Dietary pattern analysis can be performed a priori or a posteriori. The first uses indexes, which can evaluate the adequacy of food intake based on guidelines recommendations previously determined, such as Dietary Inflammatory Index (DII ${ }^{\mathrm{TM}}$ ) [9,10], Healthy Eating Index (HEI) [11] and Dietary Quality Index (DQI) [12]. The second one is based on statistical analysis of food consumption data to develop new dietary patterns, such as factor analysis and Principal Component Analysis (PCA) [3,13].

Moreover, a dietary pattern may be anti-inflammatory, as in the case of the Mediterranean diet, or be pro-inflammatory, such as Western diet, and therefore contribute to the prevention or development of CNCD $[1,3,6,14-17]$. The DII was developed and validated in 2009 [8] and updated in 2014 [9] to evaluate the inflammatory effect of diet on health and disease. The 
index is based on extensive literature review and resulted in 45 dietary parameters (macronutrients, micronutrients and bioactive compounds such as teas, flavonoids and spices) based on their influence on the inflammatory markers including interleukin (IL)-1 $\beta$, IL-4, IL-6, IL-10, tumor necrosis factor (TNF)- $\alpha$ and C-reactive protein (CRP) [18].

Some studies have identified positive associations between DII scores and overweight or obesity in Poland, Spain, USA and Mexico populations [18-21]. However, the association of this index in subjects at high cardiometabolic risk with dietary patterns has rarely been reported [18,21], especially in the Brazilian population [22].

Therefore, the hypothesis of this study is that a more pro-inflammatory diet is associated with cardiometabolic risk factors.

This study aimed to evaluate the potential association of Dietary Inflammatory Index (DII ${ }^{\mathrm{TM}}$ ) score with cardiometabolic risk factors and a priori and a posteriori dietary patterns in adults and elderly Brazilians from a Cardiovascular Health Care Program.

\section{Materials and Methods}

\subsection{Subjects}

The Cardiovascular Health Care Program (PROCARDIOUFV) performs nutritional intervention in the academic community of the Universidade Federal de Viçosa (UFV). The inclusion criteria are: age $>20$ years; diagnosis of cardiovascular disease or have cardiometabolic risk factors, as previously described [23-25].

The Ethics Committee in Human Research of the Universidade Federal de Viçosa approved the protocol of the present study (Of Ref. No. 066/2012/CEPH). All subjects provided written informed consent, according to the general recommendations of the Declaration of Helsinki. The PROCARDIO-UFV is registered in the Brazilian Registry of Clinical Trials (ReBEC: RBR-5n4y2g).

In this cross-sectional study, we included data from 248 individuals (138 women and 110 men), adults and elderly (42 \pm 16 years), participants in the PROCARDIO-UFV from March 2012 until July 2017, who presented complete medical records to study analysis.

\subsection{Food Consumption, HEI, PCA and DII}

The food intake was estimated using a 24-hour recall (24HR) using a 5-step multiple-pass method carried out by a trained dietitian, for better data collection quality [26]. Portion size was estimated using standard food quantities (grams) including food photographs and a standard manual on portions of food and household measures.

Micronutrients (iron, fiber, magnesium, vitamin C, zinc, selenium, vitamin A and vitamin B12), macronutrients, n-6 fatty acids and alcohol were analyzed using DietPRO® software, version 5.8, using Brazilian table of food composition [27].
The dietary patterns were determined by PCA, as previously described [28]. Five patterns were identified as "Traditional", "Caloric", "Unhealthy", "Healthy" and "Healthy Snacks". Scores greater than or equal to zero were considered positive for the dietary patterns. Each pattern was characterized by a group of foods as rice and tubers, beans, vegetable oils, non-leafy vegetables, meats, fish and eggs (grilled, cooked or roasted) for the "Traditional"; meat, offal and eggs (fried), processed meat, sweets and sugar, soft beverages and artificial juices for the "Caloric", "Unhealthy" was represented by fast food and pasta; "Healthy" was composed by whole grain food and nuts, milk, dairy, fruits and natural juices and finally "Healthy Snacks" by leafy vegetables, chicken salad sandwich.

For the Healthy Eating Index (HEI) analysis, the revised index for the Brazilian population was used, and the median (71 points) was considered to classify the diet as adequate (greater than 71 points) and inadequate (lower than 71 points) [29].

The design and development of DII has been described previously [8,9]. Briefly, the DII was calculated using a scoring algorithm based on a review of 1,943 articles that showed the association of 45 food parameters with six inflammatory biomarkers (IL-1b, IL-4, IL-6, IL-10, TNF- $\alpha$ and CRP). Food parameters evaluated in the articles were positively marked $(+1)$ if the effect was considered pro-inflammatory, negatively $(-1)$ in the case of an anti-inflammatory effect, or zero, if the parameters did not produce a significant change in the biomarkers. The 24HR-derived food and nutrient consumption was first adjusted for total energy (i.e., per 1000 kilocalories) and then standardized to a globally representative energy-adjusted dietary database, which was constructed based on dietary intake from 11 populations living in different regions of the world. From this, the energy-adjusted standardized dietary intake (expressed as z-scores of the referent database and then as centered proportions) was then multiplied by the literature-derived inflammatory effect score for each DII component. Individual scores were then summed to determine the overall DII (DII ${ }^{\mathrm{TM}}$ ) score for everyone, with positive scores, representing a more pro-inflammatory diet, and negative values, representing more anti-inflammatory diets.

The DII score in this study was based in the following 19 food parameters, obtained using the 24HR: n-6 fatty acids, iron, fiber, magnesium, zinc, selenium, vitamin $\mathrm{C}$, vitamin $\mathrm{A}$, vitamin B12, carbohydrates, proteins, lipids, cholesterol, trans, saturated, mono and polyunsaturated fats, energy (kcal) and alcohol. In the present study, the DII was categorized into tertiles, whereas first $(<-0.22)$, second $(\geq-0.22$ and $<0.45)$, and third $(\geq 0.45)$ tertiles were the most anti-inflammatory, neutral and the most pro-inflammatory tertile, respectively.

\subsection{Cardiometabolic Risk Factors Assessment}

Weight, height and waist circumference (WC) were measured according to the protocol standardized by 
PROCARDIO-UFV previously described [30]. The body mass index (BMI) was calculated and classified as excessive body weight to BMI $\geq 25.0 \mathrm{~kg} / \mathrm{m}^{2}$ for adults [31] and BMI $\geq 28.0 \mathrm{~kg} / \mathrm{m}^{2}$ for elderly [32]. Abdominal obesity was considered as WC $\geq 90$ for men and $\geq 80 \mathrm{~cm}$ for women [33]. Waist-to-height ratio $(\mathrm{WHtR})>0.5$ and waist-to-hip ratio $($ WHR $)>1.0$ for men and > 0.85 for women were considered a cardiometabolic risk [31]. Percentage of body fat (\%BF) was estimated by horizontal tetrapolar electric bioimpedance (Biodynamics ${ }^{\circledR} 310$ model, Washington, USA), according to the protocol proposed [34], and values $>20 \%$ for men and $>30 \%$ for women were considered as excessive body fat [35].

The blood was collected after a 12-hour fasting. Serum concentrations of glucose, HDL and LDL cholesterol, total cholesterol (TC), triglycerides (TG), ferritin and uric acid were analyzed by the enzymatic colorimetric method. The ultrasensitive immunoturbidimetry method assessed serum concentration of ultrasensitive C-reactive protein (CRP). Triglyceride-glucose (TyG) index was calculated according to the formula: Ln [fasting triglycerides (mg/dL) $\mathrm{x}$ fasting plasma glucose $(\mathrm{mg} / \mathrm{dL}) / 2]$ and Homeostasis model assessment of insulin resistance (HOMA-IR) by the formula: [(fasting glucose $(\mathrm{mg} / \mathrm{dL})) \times$ (fasting insulin $(\mu \mathrm{U} / \mathrm{mL}))]$ / 405 [36-39].

Cholesterol, triglycerides and LDL were considered elevated if values $\geq 240 \mathrm{mg} / \mathrm{dL}, \geq 150 \mathrm{mg} / \mathrm{dL}$ and $\geq 160$ $\mathrm{mg} / \mathrm{dL}$, respectively, as well as cut-off points for $\mathrm{HDL}<40 \mathrm{mg} / \mathrm{dL}$ for men and $<50 \mathrm{mg} / \mathrm{dL}$ for women $[37,40]$. Besides that, uric acid was considered elevated if $\geq 6 \mathrm{mg} / \mathrm{dL}$ [40].

CRP was categorized as recommended by the US Centers for Disease Control and Prevention (CDC) and the American Heart Association, with values $\leq 3.0 \mathrm{mg} / \mathrm{dL}$ being considered adequate and those $>10 \mathrm{mg} / \mathrm{dL}$ (presented by four individuals) excluded, since they may indicate acute inflammation [41]. For analysis of the ferritin and the TyG index, the 75th percentile of the sample was used as the cut-off point, being greater than or equal to 207 and 5.01, respectively. For HOMA-IR and fasting glucose, high values were considered above 2.71 and $\geq 100 \mathrm{mg} / \mathrm{dL}$, respectively [42].

Blood pressure was measured using a mechanical mercury sphygmomanometer (Missouri®, São Paulo, Brazil) with approximately $02 \mathrm{mmHg}$ [39] considering high blood pressure values $\geq 140 / 90 \mathrm{mmHg}$ [43]. Moreover, the participants were the ones to report medical diagnosis of diabetes, hypertension and dyslipidemias and the use of medications.

\subsection{Other Characteristics of Sample}

The information about age (years), income (did not report; up to 2 minimum wages; 2 to 4 minimum wages; 4 to 10 minimum wages and more than 10 minimum wages), smoking (never smoked or smoked), physical activity and diagnosed diseases as well as information about medicine use (statins, antihypertensive and oral hypoglycemic) was obtained by semi-structured questionnaire elaborated specially for the PROCARDIO-UFV study.

\subsection{Statistical Analysis}

Descriptive analysis were performed for the main variables of interest. The distribution of the variables was verified by means of boxplot graphs, histogram, kurtosis and skewness values. The analysis of variance (ANOVA) was used to compare averages between DII tertiles, followed by Tukey and Bonferroni post hoc tests. The Pearson's chi-squared test was used to evaluate the distribution of the qualitative variables among the DII tertiles. Poisson regression models were performed to analyze the association of DII (independent variable) with cardiometabolic risk factors and dietary patterns (dependent variables), using the second tertile (neutral inflammation) as reference. Multiple Poisson regression models were adjusted for age, sex, income, smoking, physical activity and statin, antihypertensive and oral hypoglycemic use. The Hosmer \& Lemeshow test was used to verify the fit of the final model. The prevalence ratio (PR) with 95\% confidence interval (95\% CI) was used as an effect measure. All statistical analysis were performed using SPSS software version 22.0 and Stata version 13.0, considering a significance level of $5 \%$.

\section{Results}

The mean age of the participants was 42 years, ranging from 20 to 80 years, $55.6 \%$ were female and $69.8 \%$ had excessive body weight. The mean DII was $0.15 \pm 0.84$. Those subjects with most pro-inflammatory diet (third tertile) were more likely to be women, non smokers, and non-diabetics (Table 1). They also had lower mean age and WHR, compared to the most anti-inflammatory diet (first tertile).

Regarding diet composition, subjects included in the third tertile of DII had higher mean values of energy, lipid, cholesterol, monounsaturated fat and saturated fat, while those included in the first tertile had higher intakes of carbohydrates, omega 6 , iron, fiber, magnesium, vitamin $\mathrm{C}$, zinc and polyunsaturated fatty acids (Table 2).

Interestingly, highest DII tertile (most pro-inflammatory diet) was associated with excessive body weight (PR: 1.29; 95\%CI: 1.06 - 1.58) and increased WHR (PR: 1.29; 95\%CI: 1.02-1.64) even after all adjustments. However, there was an association between DII and higher WHtR when adjusted only by sex and age (PR: 1.16; 95\%CI: 1.01-1.33) (Table 3).

In addition, the lowest tertile of DII (the most anti-inflammatory diet) was inversely associated with inadequate diet (HEI below 71 points) (PR: 0.57; 95\%CI: 0.38-0.88), while the highest tertile (the most pro-inflammatory) was directly associated with inadequate diet (PR: 1.52; 95\%CI: 1.15-2.01). From the five dietary patterns obtained by the PCA method, DII was associated with three. After all adjustments, the lowest DII tertile was associated with "Healthy" (PR: 3.71; 95\%CI: 1.54-8.90) and "Healthy snacks" (PR: 3.05; 95\%CI: 1.128.32), while the highest DII tertile was associated with more "Unhealthy" diets, (PR: 2.94; 95\%CI: 1.03-8.35) (Table 4). 
Table 1. Sociodemographic, clinical and lifestyle characteristics of sample (n=248), according to the tertiles of the E-Dietary Inflammatory Index

\begin{tabular}{|c|c|c|c|}
\hline \multirow[b]{2}{*}{ Variables } & \multicolumn{3}{|c|}{ Dietary Inflammatory Index } \\
\hline & T1 & T2 & T3 \\
\hline Age (years) $a$ & $49 \pm 15^{a}$ & $40 \pm 16^{b}$ & $38 \pm 15^{b}$ \\
\hline \multicolumn{4}{|l|}{ Sexa } \\
\hline Male & $48(43.6 \%)^{\mathrm{a}}$ & $30(27.3 \%)^{b}$ & $32(29.1 \%)^{b}$ \\
\hline Female & $34(24.6 \%)^{\mathrm{a}}$ & $53(38.4 \%)^{b}$ & $51(37 \%)^{b}$ \\
\hline \multicolumn{4}{|l|}{ Lifestyle } \\
\hline Never smokeda & $44(26.4 \%)^{a}$ & $61(36.5 \%)^{b}$ & $62(37.1 \%)^{b}$ \\
\hline Physical activity practice & $42(30.7 \%)$ & $50(36.5 \%)$ & $45(32.8 \%)$ \\
\hline \multicolumn{4}{|l|}{ Diagnosed diseases } \\
\hline Diabetics† & $19(45.2 \%)^{a}$ & $16(38.1 \%)^{a}$ & $7(16.7 \%)^{b}$ \\
\hline Hypertensive & $36(37.9 \%)$ & $32(33.7 \%)$ & $27(28.4 \%)$ \\
\hline \multicolumn{4}{|l|}{ Use of medicines } \\
\hline Oral antidiabetic $\dagger$ & $17(7 \%)^{\mathrm{a}}$ & $10(4.1 \%)^{a}$ & $5(2.1 \%)^{b}$ \\
\hline Insulin & $2(0.8 \%)$ & $4(1.6 \%)$ & 0 \\
\hline Antihypertensive $\dagger$ & $41(16.8 \%)^{\mathrm{a}}$ & $31(12.7 \%)^{\mathrm{a}}$ & $24(9.8 \%)^{b}$ \\
\hline Cholesterol reducers $\dagger$ & $33(13.6 \%)^{a}$ & $24(9.9 \%)^{a b}$ & $18(7.4 \%)^{b}$ \\
\hline Fibrates & $8(3.3 \%)$ & $4(1.6 \%)$ & $4(1.6 \%)$ \\
\hline Weight control & 0 & $2(0.8 \%)$ & $1(0.4 \%)$ \\
\hline \multicolumn{4}{|l|}{ Anthropometric } \\
\hline BMI & $28.6 \pm 5.1$ & $28.4 \pm 6.1$ & $29.1 \pm 5.0$ \\
\hline WHtR & $0.6 \pm 0.1$ & $0.6 \pm 0.1$ & $0.6 \pm 0.1$ \\
\hline WHRa & $1.0 \pm \mathbf{0 . 1}^{\mathrm{a}}$ & $0.9 \pm 0.1^{b}$ & $0.9 \pm 0.1^{b}$ \\
\hline$\% \mathrm{BF}$ & $30.4 \pm 7.3$ & $30.4 \pm 9.5$ & $30.9 \pm 7.2$ \\
\hline \multicolumn{4}{|l|}{ Biochemical } \\
\hline Triglycerides & $177.0 \pm 98.6$ & $177.9 \pm 125.1$ & $162.1 \pm 82.4$ \\
\hline TyG & $4.8 \pm 0.3$ & $4.8 \pm 0.3$ & $4.7 \pm 0.3$ \\
\hline Fasting glucose & $107.26 \pm 38.36$ & $100.32 \pm 31.02$ & $93.97 \pm 31$ \\
\hline HOMA-IR & $2.5 \pm 1.7$ & $3.0 \pm 2.9$ & $2.4 \pm 1.3$ \\
\hline Ferritin & $169.9 \pm 126.9$ & $122.0 \pm 141.6$ & $146.7 \pm 200.1$ \\
\hline CRP & $2.4 \pm 2.9$ & $2.1 \pm 2.0$ & $2.5 \pm 2.5$ \\
\hline Uric acid & $4.8 \pm 1.5$ & $4.3 \pm 1.5$ & $4.4 \pm 1.5$ \\
\hline TC & $197.5 \pm 47.8$ & $207.0 \pm 40.4$ & $212.6 \pm 41.9$ \\
\hline HDL & $44.2 \pm 11.2$ & $47.9 \pm 13.9$ & $50.1 \pm 16.1$ \\
\hline LDL & $118.3 \pm 44.1$ & $126.5 \pm 35.1$ & $129.2 \pm 36.6$ \\
\hline Non-HDL & $158.6 \pm 39.2$ & $153.3 \pm 46.8$ & $162.3 \pm 39.2$ \\
\hline
\end{tabular}

DII Tertiles Ranges: T1: $<-0.22 ; \mathrm{T} 2: \geq-0.22$ and $<0.45 ; \mathrm{T} 3: \geq 0.45 . \dagger \mathrm{P}<0.05 ; \mathrm{aP}<0.01$. BMI is in $\mathrm{kg} / \mathrm{m}^{2}$; ferritin is in $\mu g / \mathrm{L} ; \mathrm{CRP}$ is in $\mathrm{mg} / \mathrm{L}$; triglycerides, fasting glucose, uric acid, TC (total cholesterol), HDL, LDL and non-HDL (non-HDL cholesterol) are in mg/dL. WHtR: waist-to-height ratio; WHR: waist-to-hip ratio; \%BF: body fat percentage; TyG: triglyceride-glucose index; HOMA-IR: homeostasis model assessment of insulin resistance; CRP: C-reactive protein. Quantitative variables expressed as mean \pm standard deviation and categorical variables in absolute and relative values. Different letters indicate statistical significance on the same line. Values are determined using ANOVA or chi-square test.

Table 2. Energy and nutrient intake according to the tertiles of the Dietary Inflammatory Index

\begin{tabular}{|c|c|c|c|}
\hline \multicolumn{4}{|c|}{ Dietary Inflammatory Index } \\
\hline Variables & T1 & T2 & T3 \\
\hline Energyo & $1652.7 \pm 538.4^{\mathrm{a}}$ & $1564.8 \pm 500.0^{\mathrm{a}}$ & $1953.8 \pm 614.0^{b}$ \\
\hline Carbohydrate & $245.2 \pm 44.4^{\mathrm{a}}$ & $231.77 \pm 39.6^{a}$ & $208.9 \pm 47.3^{b}$ \\
\hline Protein & $81.7 \pm 20.2$ & $77.8 \pm 21.1$ & 76. $6 \pm 26.6$ \\
\hline Lipida & $76.7 \pm 14.9^{\mathrm{a}}$ & $83.9 \pm 13.3^{b}$ & $93.7 \pm 17.1^{c}$ \\
\hline Cholesterola & $182.9 \pm 121.7^{\mathrm{a}}$ & $212.7 \pm 144.8^{\mathrm{ab}}$ & $244.6 \pm 219.7^{b}$ \\
\hline Saturated fata & $24.7 \pm 6.0^{\mathrm{a}}$ & $29.2 \pm 5.7^{b}$ & $34.8 \pm 9.6^{c}$ \\
\hline Trans fat & $1.4 \pm 1.00$ & $1.8 \pm 1.4$ & $2.8 \pm 7.8$ \\
\hline MUFAa & $26.5 \pm 18.0^{\mathrm{a}}$ & $28.8 \pm 5.5^{\mathrm{a}}$ & $32.0 \pm 7.3^{b}$ \\
\hline PUFA $a$ & $17.4 \pm 4.3^{\mathrm{a}}$ & $16.5 \pm 4.8^{\mathrm{ab}}$ & $14.8 \pm 5.8^{b}$ \\
\hline Omega $6 \dagger$ & $12.0 \pm 3.8^{\mathrm{a}}$ & $11.2 \pm 3.9^{\mathrm{ab}}$ & $9.7 \pm 4.9^{b}$ \\
\hline Irona & $11.1 \pm 3.7^{\mathrm{a}}$ & $9.7 \pm 3.0^{b}$ & $8.3 \pm 3.1^{c}$ \\
\hline Fibera & $37.7 \pm 15.8^{\mathrm{a}}$ & $28.5 \pm 7.7^{\mathrm{b}}$ & $16.6 \pm 6.3^{c}$ \\
\hline Magnesiuma & $258.2 \pm 83.8^{\mathrm{a}}$ & $207.4 \pm 5.7^{b}$ & $150.5 \pm 4.9^{c}$ \\
\hline Vitamin Ca & $241.5 \pm 19.2^{\mathrm{a}}$ & $95.7 \pm 11.4^{b}$ & $56.1 \pm 9.0^{b}$ \\
\hline Zinct & $11.5 \pm 4.5^{\mathrm{a}}$ & $11.0 \pm 6.0^{\mathrm{ab}}$ & $9.5 \pm 5.3^{\mathrm{b}}$ \\
\hline Selenium & $99.6 \pm 36.0$ & $98.0 \pm 33.7$ & $92.3 \pm 31.7$ \\
\hline Vitamin A & $260.8 \pm 1034.9$ & $404.3 \pm 1122.1$ & $268.1 \pm 201.1$ \\
\hline Vitamin B12 & $4.3 \pm 7.9$ & $4.8 \pm 8.3$ & $3.9 \pm 2.8$ \\
\hline Alcohol \% v/v & $0.9 \pm 5.3$ & $0.5 \pm 4.2$ & $0.7 \pm 3.9$ \\
\hline
\end{tabular}

DII Tertiles Ranges: T1: $<-0.22 ; \mathrm{T} 2: \geq-0.22$ and $<0.45 ; \mathrm{T} 3: \geq 0.45 . \dagger \mathrm{P}<0.05 ; \propto \mathrm{P}<0.01$. MUFA: monounsaturated fatty acid; PUFA: polyunsaturated fatty acid. Energy is in kcal; Carbohydrate is in g; Protein is in g; Lipid is in g; Cholesterol is in g; Saturated fat is in g; Trans fat is in g; MUFA is in g; PUFA is in g; Omega 6 is in g; Iron is in mg; Fiber is in g; Magnesium is in mg; Vitamin C is in mg; Zinc is in mg; Selenium is in mg; Vitamin A is in mg; Vitamin B12 is in mg; Alcohol is in \%v/v. Variables expressed as mean \pm standard deviation. Different letters indicate statistical significance on the same line. Values are determined using ANOVA test. 
Table 3. Prevalence ratio for cardiometabolic risk factors according to the tertiles of the Dietary Inflammatory Index

\begin{tabular}{|c|c|c|c|c|}
\hline \multirow{2}{*}{ Outcome variables } & & \multirow{2}{*}{$\begin{array}{c}\text { Model 1 } \\
\text { PR (95\%CI) }\end{array}$} & \multirow{2}{*}{$\begin{array}{c}\text { Model } 2 \\
\text { PR (95\%CI) }\end{array}$} & \multirow{2}{*}{$\begin{array}{c}\text { Model } 3 \\
\text { PR (95\%CI) }\end{array}$} \\
\hline & & & & \\
\hline & $\mathrm{T} 1$ & $1.00(0.80-1.26)$ & $0.97(0.77-1.23)$ & $1.00(0.79-1.26)$ \\
\hline \multirow[t]{3}{*}{ Excessive body weight } & $\mathrm{T} 2$ & 1 & 1 & 1 \\
\hline & Т3 & $1.28(1.05-1.56) \dagger$ & $1.25(1.02-1.52) \dagger$ & $1.29(1.06-1.58) \dagger$ \\
\hline & $\mathrm{T} 1$ & $0.98(0.86-1.12)$ & $0.98(0.86-1.13)$ & $0.99(0.86-1.14)$ \\
\hline \multirow[t]{3}{*}{$\mathrm{WHtR}$} & $\mathrm{T} 2$ & 1 & 1 & 1 \\
\hline & T3 & $1.16(1.01-1.33) \dagger$ & $1.14(0.99-1.31)$ & $1.14(0.99-1.32)$ \\
\hline & $\mathrm{T} 1$ & $1.01(0.79-1.27)$ & $0.95(0.74-1.23)$ & $0.97(0.75-1.26)$ \\
\hline \multirow[t]{3}{*}{ WHR } & $\mathrm{T} 2$ & 1 & 1 & 1 \\
\hline & $\mathrm{T} 3$ & $1.33(1.06-1.67) \dagger$ & $1.27(1.01-1.60) \dagger$ & $1.29(1.02-1.64) \dagger$ \\
\hline & $\mathrm{T} 1$ & $1.16(0.95-1.43)$ & $1.08(0.87-1.33)$ & $1.09(0.88-1.34)$ \\
\hline \multirow[t]{3}{*}{ Excessive body fat } & $\mathrm{T} 2$ & 1 & 1 & 1 \\
\hline & $\mathrm{T} 3$ & $1.23(1.00-1.51)$ & $1.12(0.91-1.38)$ & $1.14(1.93-1.40)$ \\
\hline & $\mathrm{T} 1$ & $0.80(0.52-1.23)$ & $0.69(0.44-1.06)$ & $0.66(0.42-1.04)$ \\
\hline \multirow{3}{*}{ Fasting glucose } & $\mathrm{T} 2$ & 1 & 1 & 1 \\
\hline & $\mathrm{T} 3$ & $0.74(0.46-1.21)$ & $0.65(0.39-1.09)$ & $0.72(0.44-1.17)$ \\
\hline & $\mathrm{T} 1$ & $0.77(0.48-1.24)$ & $0.69(0.42-1.12)$ & $0.67(0.40-1.11)$ \\
\hline \multirow[t]{3}{*}{ TyG } & $\mathrm{T} 2$ & 1 & 1 & 1 \\
\hline & $\mathrm{T} 3$ & $0.57(0.32-1.00)$ & $0.57(0.32-1.01)$ & $0.56(0.32-1.00)$ \\
\hline & $\mathrm{T} 1$ & $1.05(0.60-1.84)$ & $0.93(0.54-1.60)$ & $0.99(0.57-1.72)$ \\
\hline \multirow[t]{3}{*}{ HOMA-IR } & $\mathrm{T} 2$ & 1 & 1 & 1 \\
\hline & $\mathrm{T} 3$ & $0.97(0.54-1.73)$ & $0.78(0.44-1.40)$ & 0.92(0.51-1.69) \\
\hline & $\mathrm{T} 1$ & $1.06(0.58-1.94)$ & $0.95(0.51-1.77)$ & $0.90(0.50-1.63)$ \\
\hline \multirow[t]{3}{*}{$\mathrm{TC}$} & $\mathrm{T} 2$ & 1 & 1 & 1 \\
\hline & $\mathrm{T} 3$ & $1.26(0.73-2.16)$ & $1.16(0.67-2.01)$ & $1.10(0.63-1.93)$ \\
\hline & $\mathrm{T} 1$ & $0.96(0.77-1.20)$ & $0.95(0.75-1.20)$ & $0.95(0.75-1.20)$ \\
\hline \multirow[t]{3}{*}{ HDL-C } & $\mathrm{T} 2$ & 1 & 1 & 1 \\
\hline & T3 & $0.96(0.76-1.22)$ & $0.97(0.77-1.24)$ & $1.02(0.81-1.30)$ \\
\hline & $\mathrm{T} 1$ & $1.68(0.87-3.25)$ & $1.51(0.77-2.95)$ & $1.42(0.74-2.71)$ \\
\hline \multirow[t]{3}{*}{ LDL-C } & $\mathrm{T} 2$ & 1 & 1 & 1 \\
\hline & $\mathrm{T} 3$ & $1.16(0.60-2.27)$ & $1.13(0.58-2.20)$ & $1.04(0.53-2.05)$ \\
\hline & $\mathrm{T} 1$ & $0.91(0.63-1.31)$ & $0.87(0.60-1.28)$ & $0.84(0.58-1.20)$ \\
\hline \multirow[t]{3}{*}{ Non-HDL cholesterol } & $\mathrm{T} 2$ & 1 & 1 & 1 \\
\hline & $\mathrm{T} 3$ & 1.14(0.83-1.56) & $1.13(0.82-1.56)$ & $1.03(0.75-1.40)$ \\
\hline & $\mathrm{T} 1$ & $0.97(0.69-1.34)$ & $0.92(0.67-1.27)$ & $0.92(0.67-1.26)$ \\
\hline \multirow[t]{3}{*}{ TG } & $\mathrm{T} 2$ & 1 & 1 & 1 \\
\hline & $\mathrm{T} 3$ & $0.91(0.66-1.25)$ & $0.88(0.64-1.21)$ & $0.88(0.64-1.20)$ \\
\hline & $\mathrm{T} 1$ & $0.85(0.60-1.22)$ & $0.87(0.60-1.25)$ & $0.87(0.60-1.26)$ \\
\hline \multirow[t]{3}{*}{ SBP/DBP } & $\mathrm{T} 2$ & 1 & 1 & 1 \\
\hline & $\mathrm{T} 3$ & $0.85(0.58-1.24)$ & $0.82(0.55-1.22)$ & $0.83(0.55-1.25)$ \\
\hline & $\mathrm{T} 1$ & $0.99(0.53-1.83)$ & $0.72(0.37-1.40)$ & $0.76(0.41-1.42)$ \\
\hline \multirow[t]{3}{*}{ CRP } & $\mathrm{T} 2$ & 1 & 1 & 1 \\
\hline & $\mathrm{T} 3$ & $0.93(0.45-1.92)$ & $0.73(0.34-1.58)$ & $0.71(0.33-1.51)$ \\
\hline & $\mathrm{T} 1$ & $1.13(0.60-2.13)$ & $1.20(0.59-2.44)$ & $1.34(0.58-3.13)$ \\
\hline \multirow[t]{3}{*}{ Ferritin } & $\mathrm{T} 2$ & 1 & 1 & 1 \\
\hline & $\mathrm{T} 3$ & $0.95(0.46-1.95)$ & $0.72(0.33-1.57)$ & $0.80(0.35-1.85)$ \\
\hline & $\mathrm{T} 1$ & $1.01(0.36-2.87)$ & $1.33(0.38-4.69)$ & $1.53(0.49-4.76)$ \\
\hline \multirow[t]{2}{*}{ Uric acid } & $\mathrm{T} 2$ & 1 & 1 & 1 \\
\hline & Т3 & $0.49(0.13-1.76)$ & $0.78(0.18-3.31)$ & $0.76(0.20-2.94)$ \\
\hline
\end{tabular}

DII Tertiles Ranges: $1:<-0.22 ; 2: \geq-0.22$ and $<0.45 ; 3: \geq 0.45$. $\dagger \mathrm{P}<0.05$. Excessive body weight (BMI $\geq 25 \mathrm{~kg} / \mathrm{m}^{2}$ for adults; $\geq 28 \mathrm{~kg} / \mathrm{m}^{2}$ for elderly); WHtR $>0.5$; WHR ( $>1$ for men; $>0.85$ for women);; Excessive body fat ( $\%$ BF $>20 \%$ for men; $>30 \%$ for women); Fasting glucose $\geq 100 \mathrm{mg} / \mathrm{dL}$; TyG $\geq 5.01$; HOMA-IR $\geq 2.71 ; \mathrm{TC} \geq 240 \mathrm{mg} / \mathrm{dL}$; HDL-C ( $<40 \mathrm{mg} / \mathrm{dL}$ for men; $<50 \mathrm{mg} / \mathrm{dL}$ for women); LDL-C $\geq 160 \mathrm{mg} / \mathrm{dL} ;$ Non-HDL cholesterol $\geq 160$ $\mathrm{mg} / \mathrm{Dl}$; TG $\geq 150 \mathrm{mg} / \mathrm{dL} ; \mathrm{SBP} \geq 140 \mathrm{mmHg}$ and/or DBP $\geq 90 \mathrm{mmHg}$; CRP $>3 \mathrm{mg} / \mathrm{dL}$; Ferritin $>207$ ( $\mu \mathrm{g} / \mathrm{L})$; Uric acid $\geq 6 \mathrm{mg} / \mathrm{dL}$. DII: dietary inflammatory index; PR: prevalence ratio; 95\% CI: 95\% confidence interval; WHtR: waist-to-height ratio; WHR: waist-to-hip ratio; \%BF: body fat percentage; TyG: triglyceride-glucose index; HOMA-IR: homeostasis model assessment of insulin resistance; TC: total cholesterol; HDL-C: high density lipoprotein; LDL-C: low density lipoprotein; TG: triglyceride; SBP: systolic blood pressure; DBP: diastolic blood pressure; CRP: C-reactive protein. Model 1: adjusted for age and sex. Model 2: Model $1+$ income + smoking + physical activity. Model 3: Model $2+$ statin use + antihypertensive use + oral hypoglycemic use. 
Table 4. Prevalence ratio for Healthy Eating Index and dietary patterns according to the tertiles of the Dietary Inflammatory Index

\begin{tabular}{|c|c|c|c|c|}
\hline Outcome variables & & $\begin{array}{c}\text { Model } 1 \\
\text { PR (95\%CI) }\end{array}$ & $\begin{array}{c}\text { Model } 2 \\
\text { PR (95\%CI) }\end{array}$ & $\begin{array}{c}\text { Model } 3 \\
\text { PR }(95 \% \mathrm{CI})\end{array}$ \\
\hline \multirow{3}{*}{ HEI $<71$} & $\mathrm{~T} 1$ & $0.57(0.38-0.87)^{\mathrm{a}}$ & $0.60(0.39-0.92) \dagger$ & $0.57(0.38-0.88)^{a}$ \\
\hline & $\mathrm{T} 2$ & 1 & 1 & 1 \\
\hline & T3 & $1.49(1.16-1.92)^{\mathrm{a}}$ & $1.56(1.19-2.06)^{\mathrm{a}}$ & $1.52(1.15-2.01)^{\mathrm{a}}$ \\
\hline \multirow{3}{*}{ DP Traditional } & $\mathrm{T} 1$ & $1.53(0.74-3.19)$ & $1.55(0.72-3.36)$ & $1.62(0.75-3.49)$ \\
\hline & $\mathrm{T} 2$ & 1 & 1 & 1 \\
\hline & $\mathrm{T} 3$ & $0.73(0.27-1.98)$ & $0.72(0.24-2.17)$ & $0.73(0.24-2.24)$ \\
\hline \multirow{3}{*}{ DP Caloric } & $\mathrm{T} 1$ & $0.55(0.20-1.49)$ & $0.67(0.23-1.95)$ & $0.56(0.20-1.59)$ \\
\hline & $\mathrm{T} 2$ & 1 & 1 & 1 \\
\hline & $\mathrm{T} 3$ & $0.97(0.45-2.12)$ & $1.01(0.42-2.40)$ & $0.89(0.37-2.15)$ \\
\hline \multirow{3}{*}{ DP Unhealthy } & $\mathrm{T} 1$ & $1.49(0.54-4.15)$ & $2.23(0.67-7.40)$ & $2.37(0.73-7.65)$ \\
\hline & $\mathrm{T} 2$ & 1 & 1 & 1 \\
\hline & T3 & $1.88(0.79-4.45)$ & $2.89(1.00-8.38)$ & $2.94(1.03-8.35) \dagger$ \\
\hline \multirow{3}{*}{ DP Healthy } & T1 & $3.00(1.36-6.59)^{a}$ & $3.70(1.54-8.89)^{\mathrm{a}}$ & $3.71(1.54-8.90)^{a}$ \\
\hline & $\mathrm{T} 2$ & 1 & 1 & 1 \\
\hline & $\mathrm{T} 3$ & $1.26(0.49-3.24)$ & $1.43(0.49-4.20)$ & $1.32(0.46-3.83)$ \\
\hline \multirow{3}{*}{ DP Healthy snacks } & $\mathrm{T} 1$ & $3.32(1.18-9.36) \dagger$ & $3.11(1.12-8.62) \dagger$ & $3.05(1.12-8.32) \dagger$ \\
\hline & $\mathrm{T} 2$ & 1 & 1 & 1 \\
\hline & $\mathrm{T} 3$ & $0.61(0.15-2.48)$ & $0.38(0.08-1.89)$ & $0.40(0.08-2.01)$ \\
\hline
\end{tabular}

DII Tertiles Ranges: $1:<-0.22 ; 2: \geq-0.22$ and $<0.45 ; 3: \geq 0.45$. $\dagger \mathrm{P}<0.05$; $\propto \mathrm{P}<0.01$. DII: dietary inflammatory index; PR: prevalence ratio; 95\% CI: 95\% confidence interval; HEI: Healthy Eating Index; DP: dietary pattern. Model 1: age + sex. Model 2: Model $1+$ income + smoking + physical activity. Model 3: Model $2+$ statin use + antihypertensive use + oral hypoglycaemic use.

\section{Discussion}

The present study demonstrated that the most pro-inflammatory DII scores were associated with excess adiposity in adults and elderly individuals with cardiometabolic risk factors. We emphasize that this is one of the first studies that investigated the DII with cardiovascular risk factors and dietary patterns of the Brazilian population. Previous study carried out with multiple sclerosis patients in Brazil verified that the DII score was directly correlated with BMI in those patients in the progressive stage of the disease $(r=0.556, p=0.025)$ [44], though the other study carried out in Brazil did not find an association between DII with insulin resistance and metabolic syndrome [22].

Our findings are corroborated by other studies in Spain and the USA $[17,45,46]$. Altogether, results suggest diet-induced inflammation may contribute to increasing or maintaining excessive body weight. The relationship between inflammation and adiposity excess may be bidirectional - overweight may induce inflammation, whereas a pro-inflammatory diet may lead to increasing or maintaining excess adiposity [47]. One possible mechanism that explains this relationship is the activation of molecular processes associated with Toll-like receptors and Nod-type receptors, which in turn induce the activation of inflammatory markers in adipose tissue [48]. Furthermore, a meta-analysis has identified significant association between pro-inflammatory diet and risk for CVD events and mortality [49].

Although this study found no association between DII with other cardiometabolic risk factors as we expected, other studies also did not observe such an association [20,50-53]. Noteworthy, the mean of the DII (0.15) of our sample did not characterize a pro-inflammatory diet in general, but in the ORISCAV-LUX study conducted with 1352 people they also did not present a pro-inflammatory diet in general [20]. Our results are different from those observed in other studies in which the DII was much higher. Cross-sectional analysis from Polish-Norwegian Study (PONS) and National Health and Nutrition Examination Survey (NHANES) presented a DII mean of $0.93 \pm 1.44$ [47] and $0.87 \pm 1.08$ [54], respectively. In a case control study with women that aborted, the DII was $1.51 \pm 0.63$ in cases and $1.22 \pm 0.63$ in controls [55]. Based on that, this may have contributed to the lack of association with some anthropometric and biochemical markers related to cardiometabolic risk in our study.

In addition, higher percentage of diabetics, smokers or ex-smokers, i.e.,individuals who are at elevated risk for the development of CVD were in the first tertile of the DII (more anti-inflammatory diet). These individuals may have received medical and nutritional guidance at some point, and had become more concerned about their health, and therefore began consuming a more healthy diet. This previous guidance in life-course of subjects with cardiometabolic risk may have contributed to the lack of association with other cardiometabolic markers. The same was observed in other studies in which people with metabolic syndrome, particularly with abdominal obesity and high blood pressure, had a diet with an antiinflammatory profile [20].

We also presented a positive association between most anti-inflammatory diet and healthier dietary patterns, such as "Healthy" and "Healthy snacks" from PCA (a posteriori method), as well as positive association between most pro-inflammatory diet and inadequate diet (a priori method) and "Unhealthy" pattern (a posteriori method). We highlight that this is one of the few studies that evaluated the association between DII and dietary patterns. The dietary pattern may present anti-inflammatory characteristics, as in the case of the Mediterranean diet, or pro-inflammatory, such as Western diet, contributing to the prevention or development of CNCD $[1,3,4,13]$. This 
difference is due to the nutritional composition of these food patterns, the first one characterized by the high content of anti-inflammatory nutrients and antioxidants, and the second by excessive consumption of foods of animal origin, sources of saturated fat and cholesterol, responsible for changes in the lipid profile [56]. The pro-inflammatory diet activates the immune system (with secretion of pro-inflammatory cytokines) and increases the expression of adhesion molecules, with consequent inflammatory process in vascular tissue $[18,49,58]$. On the other hand, studies have shown that the Vegetarian and Mediterranean diets reduce inflammatory markers such as CRP and IL-6 and improve endothelial function $[5,13,59]$.

This is the first study to associate DII with anthropometric and biochemical variables, and dietary patterns in Brazilians with cardiovascular risk. An additional strength is the use of Dietary Inflammatory Index to evaluate these associations, which eliminates any influence of energy intake. Therefore, we suggest that other studies should be performed with different age groups and with longitudinal design. As limitations, we used a 24-hour recall, which does not reflect a habitual intake. However, this method has been used thoroughly with success in other epidemiologic studies [60,61], including DII analyses [1,45,46,54,58,62,63]. Although we were able to compute the DII from only 19 of the 45 potential items of food and nutrients that could be used to calculate this index, other published studies also derive DII scores from a sub-optimal number of items, and the ability to still detect significant associations suggests that this has only caused to a potential underestimated of the associations [1,52,58,64,65].

\section{Conclusions}

In this population of Brazilian middle-aged and elderly adults, the most pro-inflammatory diet was observed in individuals with excessive body weight and in those with a worse dietary pattern, diagnosed both by a priori and $a$ posteriori method. These results contribute to a better understanding of the role of diet on inflammatory processes related to excess adiposity in a population with cardiovascular risk, a common situation among Brazilians. More studies with longitudinal design are required to discern the association between diet associated inflammation and cardio-metabolic risk factors in other south American populations of high-risk adults.

\section{Acknowledgements}

We thank the participants of this study and the PROCARDIO-UFV team for excellent technical assistance.

\section{Funding}

This work was supported by the Coordenação de Aperfeiçoamento de Pessoal de Nível Superior (CAPES, Finance Code 001), FAPEMIG (Minas Gerais State
Agency for Research and Development). HHM Hermsdorff is CNPq Research Productivity Fellows.

\section{Statement of Competing Interests}

The authors declared no conflict of interest. However, we do wish to disclose that Dr. James R. Hébert owns controlling interest in Connecting Health Innovations LLC (CHI), a company planning to license the right to his invention of the dietary inflammatory index (DII) from the University of South Carolina in order to develop computer and smart phone applications for patient counseling and dietary intervention in clinical settings. Dr. Nitin Shivappa is an employee of $\mathrm{CHI}$.

\section{References}

[1] Shivappa N, Hebert JR, Marcos A, Diaz LE, Gomez S, Nova E, et al. Association between dietary inflammatory index and inflammatory markers in the HELENA study. Mol Nutr Food Res 2017;61:1-23.

[2] Shivappa N, Steck S, Hurley TG, Hussey JR, Ma Y, Ockene IS, et al. A population-based dietary inflammatory index predicts levels of C-reactive protein in the Seasonal Variation of Blood Cholesterol Study (SEASONS). Public Health Nutr 2014; 17: 1825-1833.

[3] Silveira BKS, Oliveira TMS, Andrade PA, Hermsdorff HHM, Rosa CDOB, Franceschini SDCC. Dietary Pattern and Macronutrients Profile on the Variation of Inflammatory Biomarkers: Scientific Update. Cardiol Res Pract 2018; 2018.

[4] Denova-Gutierrez E, Munoz-Aguirre P, Shivappa N, Hebert JR, Tolentino-Mayo L, Batis C, et al. Dietary Inflammatory Index and Type 2 Diabetes Mellitus in Adults: The Diabetes Mellitus Survey of Mexico City. Nutrients 2018;10.

[5] Petersen KS, Flock MR, Richter CK, Mukherjea R, Slavin JL, Kris-Etherton PM. Healthy Dietary Patterns for Preventing Cardiometabolic Disease: The Role of Plant-Based Foods and Animal Products. Curr Dev Nutr 2017; 1: cdn.117.001289.

[6] World Health Statistics 2018: Monitoring Health for the Sustainable Development Goals 2018.

[7] Calton EK, James AP, Pannu PK, Soares MJ. Certain dietary patterns are beneficial for the metabolic syndrome: Reviewing the evidence. Nutr Res 2014; 34: 559-68.

[8] Cavicchia PP, Steck SE, Hurley TG, Hussey JR, Ma Y, Ockene IS et al. A New Dietary Inflammatory Index Predicts Interval Changes in Serum High-Sensitivity C-Reactive Protein. J Nutr 2009; 139: 2365-72.

[9] Shivappa N, Steck S, Hurley T, Hussey J, Hebert J. Designing and developing a literature-derived, population-based dietary inflammatory index. Public Health Nutr 2014; 17: 1689-96.

[10] Kennedy ET, Ohls J, Carlson S, Fleming K. The Healthy Eating Index: Design and applications. J Am Diet Assoc 1995; 95: 1103-8.

[11] Fisberg RM, Slater B, Barros. Healthy Eating Index: evaluation of adapted version and its applicability 2004; 17: 301-8.

[12] Hosseini Z, Whiting SJ, Vatanparast H. Current evidence on the association of the metabolic syndrome and dietary patterns in a global perspective. Nutr Res Rev 2016; 29: 152-62.

[13] Barbaresko J, Koch M, Schulze MB, Nöthlings U. Dietary pattern analysis and biomarkers of low-grade inflammation: A systematic literature review. Nutr Rev 2013; 71: 511-27.

[14] Neale EP, Batterham MJ, Tapsell LC. Consumption of a healthy dietary pattern results in significant reductions in C-reactive protein levels in adults: A meta-analysis. Nutr Res 2016; 36: 391-401.

[15] Clark RL, Famodu OA, Holásková I, Infante AM, Murray PJ, Olfert IM, et al. Educational intervention improves fruit and vegetable intake in young adults with metabolic syndrome components. Nutr Res 2019; 62: 89-100.

[16] Turner-McGrievy GM, Wirth MD, Shivappa N, Wingard EE, Fayad R, Wilcox S, et al. Randomization to plant-based dietary 
approaches leads to larger short-term improvements in Dietary Inflammatory Index scores and macronutrient intake compared with diets that contain meat. Nutr Res 2015; 35: 97-106.

[17] Ruiz-Canela M, Zazpe I, Shivappa N, Hébert JR, Sánchez-Tainta A, Corella D, et al. Dietary inflammatory index and anthropometric measures of obesity in a population sample at high cardiovascular risk from the PREDIMED (PREvención con DIeta MEDiterránea) trial. Br J Nutr 2015; 113: 984-95.

[18] Garcia-Arellano A, Ramallal R, Ruiz-Canela M, Salas-Salvadó J, Corella D, Shivappa N, et al. Dietary inflammatory index and incidence of cardiovascular disease in the PREDIMED study. Nutrients 2015; 7: 4124-38.

[19] Neufcourt L, Assmann KE, Fezeu LK, Touvier M, Graffouillère L, Shivappa N, et al. Prospective Association Between the Dietary Inflammatory Index and Cardiovascular Diseases in the SUpplémentation en VItamines et Minéraux AntioXydants (SU.VI.MAX) Cohort. J Am Heart Assoc 2016; 5: 1-11.

[20] Alkerwi A, Shivappa N, Crichton G, Hébert JR. No significant independent relationships with cardiometabolic biomarkers were detected in the observation of cardiovascular risk factors in luxembourg study population. Nutr Res 2014; 34: 1058-65.

[21] Wirth MD, Shivappa N, Hand GA, Hurley G, Drenowatz C, McMahon D, et al. Anti-inflammatory Dietary Inflammatory Index scores are associated with healthier scores on other dietary indices 2017; 36:214-9.

[22] Carvalho CA, Silva AAM, Assunção MCF, Fonseca PCA, Barbieri MA, Bettiol H, et al. The dietary inflammatory index and insulin resistance or metabolic syndrome in young adults. Nutrition 2019;58: 187-93.

[23] Rodrigues JS, Almeida AP de, Rosa C de OB, Hermsdorff HHM. Are Body Fat and Uric Acid Associated with Cardiovascular Risk Scores? Cross-Sectional Analysis in the PROCARDIO-UFV Trial. Int J Cardiovasc Sci 2017; 30: 313-24.

[24] Almeida AP de, Rocha DMUP, Mendonça LM, Novaes JF de, Hermsdorff HHM. Carotenoid and polyphenol consumption in subjects with cardiometabolic risk. Nutr Clínica y Dietética Hosp 2016;36:138-45.

[25] Kelly B, Silveira S, Novaes JF De, Reis NDA, Lourenço LP, Helena A, et al. Sociodemographic and Lifestyle Factors Are Associated with Diet Quality in Cardiometabolic Risk Subjects. $J$ Food Nutr Res 2019;7:141-7.

[26] Conway JM, Ingwersen LA, Vinyard BT, Moshfegh AJ. Effectiveness of the US Department of Agriculture 5-step multiple-pass method in assessing food intake in obese and nonobese women. Am J Clin Nutr 2003; 77: 1171-8.

[27] BRASIL. Tabela Brasileira de Composição de Alimentos/NEPAUNICAMP 2011, 4th ed, Campinas.

[28] Silveira BKS, Novaes JF De, Reis N de A, Lourenço LP Capobiango AHM, Vieira SA, et al. "Traditional" and "Healthy" Dietary Patterns Are Associated with Low Cardiometabolic Risk in Brazilian Subjects. Cardiol Res Pract 2018; 2018: 1-11.

[29] Previdelli ÁN, Andrade SC de, Pires MM, Ferreira SRG, Fisberg RM, Marchioni DM. Índice de Qualidade da Dieta Revisado para população brasileira. Rev Saude Publica 2011; 45: 794-8.

[30] Silva HA da, Carraro JCC, Bressan J, Hermsdorff HHM. Relation between uric acid and metabolic syndrome in subjects with cardiometabolic risk. Einstein (São Paulo) 2015; 13: 202-8.

[31] World Health Organization. Obesity: Preventing and Managing the Global Epidemic. vol. 894. Geneva: 1998. doi:ISBN 924 1208945.

[32] Organização Panamericana de Saúde. XXXVI Reunión del Comitê Asesor de Ivestigaciones en Salud - Encuestra Multicêntrica - Salud Beinestar y Envejecimeiento (SABE) en América Latina e el Caribe - Informe preliminar. Washington, D.C: 2002.

[33] De Oliveira A, Cocate PG, Hermsdorff HHM, Bressan J, De Silva MF, Rodrigues JA, et al. Waist circumference measures: Cutoff analyses to detect obesity and cardiometabolic risk factors in a Southeast Brazilian middle-aged men population - A cross-sectional study. Lipids Health Dis 2014; 13: 1-8.

[34] Lukaski HC, Bolonchuk WW, Hall CB, Siders WA. Validation of tetrapolar bioelectrical impedance method to assess human body composition. J Appl Physiol 1986; 60: 1327-32.

[35] Bray G, Bouchard C, James W. Definitions and proposed current classifications of obesity. In: Bray GA, Bouchard C, James WPT E (Org. ). In: Handbook of obesity. New York Marcel Dekker 1998: $31-40$.
[36] Simental-Mendía LE, Rodríguez-Morán M, Guerrero-Romero F. The Product of Fasting Glucose and Triglycerides As Surrogate for Identifying Insulin Resistance in Apparently Healthy Subjects. Metab Syndr Relat Disord 2008; 6: 299-304.

[37] Sociedade Brasileira de Cardiologia. V Diretriz Brasileira de Dislipidemias e Prevenção da Aterosclerose. Arq Bras Cardiol 2013; 101: 01-22.

[38] Hanak V, Munoz J, Teague J, Stanley A, Bittner V. Accuracy of the triglyceride to high-density lipoprotein cholesterol ratio for prediction of the low-density lipoprotein phenotype $B$. Am J Cardiol 2004;94:219-22.

[39] Sociedade Brasileira de Cardiologia. VI Diretrizes Brasileiras de Hipertensão. Arq Bras Cardiol 2010; 95: 1-51.

[40] Sociedade Brasileira de Cardiologia. I Diretriz Brasileira de Prevenção Cardiovascular. Arq Bras Cardiol 2013;101.

[41] Pearson TA, Mensah GA, Alexander RW, Anderson JL, Cannon $\mathrm{RO}$, Criqui $\mathrm{M}$, et al. Markers of inflammation and cardiovascular disease: Application to clinical and public health practice: A statement for healthcare professionals from the centers for disease control and prevention and the American Heart Association. Circulation 2003; 107: 499-511.

[42] Sociedade Brasileira de Diabetes. Diretrizes- Sociedade Brasileira de Diabetes 2017-2018. Editora Cl. São Paulo: 2017.

[43] Brazilian Society of Cardiology (BSC). 7th Brazilian Guidelines of Hypertension. Arq Bras Cardiol 2016; 107: 1-83.

[44] Da Costa Silva BY, De Carvalho Sampaio HA, Shivappa N, Hébert J, Silva Albuquerque L Da, Ferreira Carioca AA, et al. Interactions between dietary inflammatory index, nutritional state and Multiple Sclerosis clinical condition. Clin Nutr ESPEN 2018; 26: 35-41.

[45] Shin D, Hur J, Cho E-H, Chung H-K, Shivappa N, Wirth MD, et al. Pre-Pregnancy Body Mass Index Is Associated with Dietary Inflammatory Index and C-Reactive Protein Concentrations during Pregnancy. Nutrients 2017;9:351.

[46] Shivappa N, Steck SE, Hussey JR, Ma Y, Hebert JR. Inflammatory potential of diet and all-cause, cardiovascular, and cancer mortality in National Health and Nutrition Examination Survey III Study. Eur J Nutr 2017; 56: 683-92.

[47] Jin C, Flavell RA. Innate sensors of pathogen and stress: Linking inflammation to obesity. J Allergy Clin Immunol 2013; 132: 287-94.

[48] Salas-Salvadó J, Bulló M, García-Lorda P, Figueredo R, Del Castillo D, Bonada A, et al. Subcutaneous adipose tissue cytokine production is not responsible for the restoration of systemic inflammation markers during weight loss. Int J Obes 2006; 30: 1714-20.

[49] Shivappa N, Godos J, Hébert JR, Wirth MD, Piuri G, Speciani AF, et al. Dietary inflammatory index and cardiovascular risk and mortality - a meta-analysis. Nutrients 2018; 10: 1-15.

[50] Wirth M, Burch J, Shivappa N, Violanti JM, Burchfiel CM, Fekedulegn D, et al. Association of a Dietary Inflammatory Index with Inflammatory Indices and the Metabolic Syndrome among Police Officers. J Occup Environ Med - LWW Journals 2015; 56: 986-9.

[51] Almeida-De-Souza J, Santos R, Barros R, Abreu S, Moreira C, Lopes L, et al. Dietary inflammatory index and inflammatory biomarkers in adolescents from LabMed physical activity study. Eur J Clin Nutr 2018;72:710-9.

[52] Sokol A, Wirth MD, Manczuk M, Shivappa N, Zatonska K, Hurley TG, et al. Association between the dietary inflammatory index, waist-to-hip ratio and metabolic syndrome. Nutr Res 2016; 36: 1298-303.

[53] M S Eid N, Albadri A-R, Alshobragi K, Sharqawi N, Albar R, Altaf A. Assessing inflammation in obese patients using DII dietary inflammatory index - A pilot cross sectional study in Jeddah, Saudi Arabia in the year 2017. J Food Nutr Res 2018; 6: 137-45.

[54] Wirth M, Burch J, Shivappa N, Steck SE, Hurley TG, Vena JE, et al. Dietary Inflammatory Index Scores Differ by Shiftwork Status: NHANES 2005-2010. J Occup Environ Med - LWW Journals 2015; 56: 145-8.

[55] Vahid F, Shivappa N, Hekmatdoost A, Hebert JR, Hossein SD, Sadeghi M. Association between Maternal Dietary Inflammatory Index (DII) and Abortion in Iranian Women and Validation of DII with Serum Concentration of Inflammatory Factors: Case-Control Study. Appl Physiol Nutr Metab 2017; 42: 511-6. 
[56] Kahleova H, Levin S, Barnard ND. Vegetarian Dietary Patterns and Cardiovascular Disease. Prog Cardiovasc Dis 2018; 61: 54-61.

[57] Mohseni-Takalloo S, Mirmiran P, Hosseini-Esfahani F, Azizi F. Dietary Fat Intake and Its Relationship with Serum Lipid Profiles in Tehranian Adolescents. J Food Nutr Res 2014; 2: 330-4.

[58] Camargo-Ramos CM, Correa-Bautista JE, Correa-Rodríguez M, Ramírez-Vélez R. Dietary inflammatory index and cardiometabolic risk parameters in overweight and sedentary subjects. Int J Environ Res Public Health 2017; 14.

[59] Schwingshackl L, Hoffmann G. Mediterranean dietary pattern, inflammation and endothelial function: A systematic review and meta-analysis of intervention trials. Nutr Metab Cardiovasc Dis 2014; 24: 929-39.

[60] Filgueiras MDS, Suhett LG, Silva MA, Rocha NP, de Novaes JF. Lower vitamin D intake is associated with low HDL cholesterol and vitamin D insufficiency/deficiency in Brazilian children. Public Health Nutr 2018; 21: 2004-12.

[61] Andrade PA, Hermsdorff HHM, Leite JIA, Shivappa N, Hebert JR, Henriques HKF, et al. Baseline Pro-inflammatory Diet Is
Inversely Associated with Change in Weight and Body Fat 6 Months Following-up to Bariatric Surgery. Obes Surg 2018.

[62] Wirth MD, Shivappa N, Hurley TG, Hebert JR. Association between previously diagnosed circulatory conditions and a dietary inflammatory index. Nutr Res 2016; 36: 227-33.

[63] Na W, Kim M, Sohn C. Dietary inflammatory index and its relationship with high-sensitivity C-reactive protein in Korean: data from the health examinee cohort. J Clin Biochem Nutr 2018; 62: 83-8.

[64] Ramallal R, Toledo E, Martinez-Gonzalez MA, HernandezHernandez A, Garcia-Arellano A, Shivappa N, et al. Dietary Inflammatory Index and Incidence of Cardiovascular Disease in the SUN Cohort. PLoS One 2015; 10:e135221.

[65] Shivappa N, Hebert JR, Anderson LA, Shrubsole MJ, Murray LJ, Getty LB, et al. Dietary inflammatory index and risk of reflux oesophagitis, Barrett's oesophagus and oesophageal adenocarcinoma: a population-based case - control study 2017: $1-9$

(C) The Author(s) 2019. This article is an open access article distributed under the terms and conditions of the Creative Commons Attribution (CC BY) license (http://creativecommons.org/licenses/by/4.0/). 